\title{
Probing Peptide Fragment Ion Structures by Combining Sustained Off-Resonance Collision-Induced Dissociation and Gas-Phase H/D Exchange (SORI-HDX) in Fourier Transform Ion-Cyclotron Resonance (FT-ICR) Instruments
}

\author{
Árpád Somogyi \\ Department of Chemistry, University of Arizona, Tucson, Arizona, USA
}

The usefulness of gas-phase $\mathrm{H} / \mathrm{D}$ exchange is demonstrated to probe heterogeneous fragment and parent ion populations. Singly and multiply protonated peptides/proteins were fragmented by using sustained off-resonance irradiation collision-induced dissociation (SORI$\mathrm{CID}$ ). The fragments and the surviving precursor ions then all undergo $\mathrm{H} / \mathrm{D}$ exchange in the gas-phase with either $\mathrm{D}_{2} \mathrm{O}$ or $\mathrm{CD}_{3} \mathrm{OD}$ under the same experimental conditions. Usually, 10 to $60 \mathrm{~s}$ of reaction time is adequate to monitor characteristic differences in the H/D exchange kinetic rates. These differences are then correlated to isomeric ion structures. The SORI-HDX method can be used to rapidly test fragment ion structures and provides useful insights into peptide fragmentation mechanisms. (J Am Soc Mass Spectrom 2008, 19, 1771-1775) (c) 2008 Published by Elsevier Inc. on behalf of American Society for Mass Spectrometry

$\mathrm{M}$ odern tandem mass spectrometry (MS/MS) is an advanced and highly versatile experimental technique that can provide detailed structural information on a wide variety of compounds, including peptides. MS/MS fragmentation spectra can easily be obtained by using different ion activation techniques. Although gas-phase collision-induced dissociation (CID) is still the most widely used ion activation method, other methods, such as infrared multiphoton dissociation (IRMPD) and electron capture or electron-transfer dissociation (ECD and ETD), are taking an increasing share in ion dissociation studies. Fourier transform ion cyclotron resonance (FT-ICR) and Orbitrap (OT) analyzers separate ions with ultrahigh resolution and mass accuracy at the sub ppm level, allowing us to achieve more reliable ion assignments and sequence determination and/or protein identification.

In spite of the tremendous success, there is still much to do to improve the reliability of search engines that are used to sequence peptides based on MS/MS data. One possibility is to include fragments' intensities into the applied fragmentation models. It is well known, however, that MS/MS spectra of protonated peptides depend on the ion activation method and also the MS/MS instrument used. To better understand peptide

Address reprint requests to Dr. Á. Somogyi, Department of Chemistry, University of Arizona, 1306 E. University, P.O. Box 210041, Bldg. 41, Tucson, AZ 85721, USA. E-mail: asomogyi@u.arizona.edu fragmentation is, therefore, still an important area of research not only for fundamental reasons but also for sequencing aspects.

Excellent mechanistic studies on peptide fragmentation have been performed by different groups, the main results of which are "summarized" by the mobile proton model $[1,2]$ and the more recent pathways in competition (PIC) model [3]. In short, the mobile proton model states that upon ion activation, the proton(s) added to a peptide migrate to various sites before fragmentation and will trigger charge directed cleavages. Thus, the proton migration is a "prerequisite" for inducing fragmentation but a detailed energetic and kinetic characterization of the main fragmentation pathways (i.e., the application of the PIC model) is necessary to describe the relative fragment ion abundances.

We describe here a relatively simple experimental method that can be used to obtain information on fragment ion structures. The method is based on gasphase $\mathrm{H} / \mathrm{D}$ exchange (HDX) between fragment ions and $\mathrm{D}_{2} \mathrm{O}$ or $\mathrm{CD}_{3} \mathrm{OD}$ in an FT-ICR cell. The mechanism of HDX in the gas phase has been studied by Beauchamp and co-workers [4]. They suggested that relay-type H/D exchanges require two protonation sites with similar local proton affinities, which can be spatially bounded by the $\mathrm{D}_{2} \mathrm{O}$ or $\mathrm{CD}_{3} \mathrm{OD}$ reagent molecule. The traditional HDX technique has been used for many years in conjunction with ion structure investigations including not only protonated peptides [5] but 
also, as we reported recently, uranyl citrate complexes [6]. Here we propose the use of gas-phase HDX after ion activation and dissociation to probe the structure of peptide fragments. A similar HDX technique has been used by O'Hair and co-workers to probe polyglycine $b$ fragments in an ion trap instrument [7] but, surprisingly, the method has not received great attention. We tested the method on an FT-ICR instrument by using sustained off-resonance irradiation collisional activation (SORI-CID) and also with a SORI/resonance excitation (RE) ion activation [8] so that we suggest to abbreviate the method as SORI(RE)-HDX. The method is easy to implement (i.e., it does not require too much hardware modifications) and can, potentially, be used with IRMPD or ECD as well. The results we obtained so far for protonated peptides and small proteins are promising and indicate that useful structural information can be obtained for all fragments under the same experimental conditions at the same time. We hope that the SORI(RE)-HDX method can be used as a complementary technique to IR ion spectroscopy $[9,10]$ or ion mobility $[11,12]$, which are becoming more and more popular in ion structure analyses.

\section{Experimental}

The described method was implemented and tested on an IonSpec (Lake Forrest, CA) 4.7 T FT-ICR instrument. SORI-CID with Ar collision gas was used to induce fragmentation of positively charged precursors. In some cases, a short RE pulse was also used $30 \mathrm{~ms}$ after the SORI excitation to induce high-energy fragmentation in the ICR cell (see Reference 8 for further details). Protonated peptides were generated from ca. $10 \mu \mathrm{M}$ $\mathrm{MeOH}: \mathrm{H}_{2} \mathrm{O}$ 1:1 solutions (containing 2\% acetic acid) by an Analytica (Branford, CT) second-generation electrospray (ESI) source with standard ESI conditions. Peptides were purchased from Sigma (St. Louis, MO) and were used without further purification.

The FT-ICR instrument was modified in-house for HDX studies by incorporating the pulsed-leak configuration described by Jiao et al. [13]. Typical $\mathrm{D}_{2} \mathrm{O}$ and $\mathrm{CD}_{3} \mathrm{OD}$ pressures were $3-5 \times 10^{-9}$ torr and $3-8 \times 10^{-7}$ torr, respectively, with a base pressure in the ICR analyzer of $7 \times 10^{-11}$ torr. A typical ion selection/ activation/HD exchange (SORI(RE)-HDX) sequence is shown in Figure S1 (Supplementary Material), which can be found in the electronic version of this article. The precursor ions can be monoisotopically selected, which is desirable but not always necessary. The HDX reaction time and the gap between the SORI(RE) activation and the beginning of the HDX are easy to modify so relative kinetic rates can be measured.

\section{Results and Discussion}

First, an experimentally and theoretically well studied peptide ion, the protonated leucine enkephalin [YGGFL +
$\mathrm{H}\left[^{+}\right.$, was studied (see Figure 1 for the SORI-HXD spectrum).

Some noticeable differences between the relative $\mathrm{H} / \mathrm{D}$ exchange kinetics for certain fragments are clearly detected. For example, the precursor ion and the $\mathrm{a}_{4}$ and $\left[\mathrm{a}_{4}-\mathrm{NH}_{3}-\mathrm{G}\right]^{+}$fragments show limited HDX reactivity (up to one or two $\mathrm{H} / \mathrm{D}$ exchanges) within the $10 \mathrm{~s}$ time frame; meanwhile the $\left[\mathrm{MH}-\mathrm{H}_{2} \mathrm{O}\right]^{+}$, the $\mathrm{b}_{4}$ and $\left[\mathrm{a}_{4}-\right.$ $\left.\mathrm{NH}_{3}\right]^{+}$fragments undergo several (3 and 4) H/D exchanges.

Water loss from the C-terminus [14] leads to the YGGFL $_{\text {oxa }}$ structure that is terminated by a C-terminal oxazolone ring. Likely, the energy gap between the N-terminal amino and C-terminal oxazolone protonated forms is small $[9,10]$ and this leads to rapid HDX of the $\left[\mathrm{MH}-\mathrm{H}_{2} \mathrm{O}\right]^{+}$fragment.

Polfer et al. provided evidence on the linear structure of the $b_{4}$ fragment $\left(Y_{\text {GGF }}\right.$ oxa ) of leucine enkephalin as well. They calculated a $\sim 1 \mathrm{kcal} / \mathrm{mol}$ energy gap between the $\mathrm{N}$-terminal amino and $\mathrm{C}$-terminal oxazolone protonated forms and showed that the two termini interact for both protonated forms. These explain the significant HDX observed for $b_{4}$ in our experiment. Similarly, the IR spectrum and modeling data indicate [10] that a significant fraction of the $a_{4}$ population is in the cyclic form. In good agreement with this, our experiments indicate a limited HDX activity for this ion.

Vachet et al. [15] found that using long reaction times, the $a_{4}-\mathrm{NH}_{3}-\mathrm{G}$ ion is formed on the $a_{4} \rightarrow \mathrm{a}_{4}-\mathrm{NH}_{3} \rightarrow$ $\mathrm{a}_{4}-\mathrm{NH}_{3}-\mathrm{G}$ reaction cascade. Their mechanism involves a cyclic $a_{4}-\mathrm{NH}_{3}$ isomer with a fixed charge (lacks a mobile proton) that is not expected to undergo any HDX. However, in our experiments the $a_{4}-\mathrm{NH}_{3}$ population rapidly undergoes numerous exchanges. Van Stipdonk and co-workers have proposed an alternative mechanism [16] that operates only with linear intermediates that are all supposed to undergo rapid HDXs. Our HDX data, therefore, suggest that either the Vachet cyclic $a_{4}-N_{3}$ isomer is a short living intermediate or the $\mathrm{a}_{4}-\mathrm{NH}_{3}-\mathrm{G}$ fragment is predominantly formed by the Van Stipdonk mechanism.

The ions associated with the HDXs of the "famous" $b_{3} / y_{2}$ ion pair (see inset in Figure 1 ) are clearly separated in the ICR cell. Both ions exchange up to six H/Ds [for ion separation, see, e.g., the $b_{3}+d_{5}(m / z 283.1429$, calc.: 283.1450) and $\mathrm{y}_{2}+d_{4}(m / z 283.1950$, calc.: 283.1954) ion pair].

Another model peptide, the singly protonated $G_{5} R$, has also been investigated (Figure 2). The precursor ion $[\mathrm{M}+\mathrm{H}]^{+}$exchanges rapidly, and the rate is definitely slower for the $\left[\mathrm{MH}-\mathrm{H}_{2} \mathrm{O}\right]^{+},\left[\mathrm{MH}-\mathrm{NH}_{3}\right]^{+}$, and $[\mathrm{MH}$ $\left.-2 \mathrm{NH}_{3}-\mathrm{H}_{2} \mathrm{O}\right]^{+}$ions. It is not recognizable in Figure 2 but the $b_{2}$ ion exchanges three Hs to Ds. In fact, the main ion at $m / z 118$ is not the $b_{2}+d_{3}$ ion $\left(\mathrm{C}_{4} \mathrm{H}_{4} D_{3} \mathrm{~N}_{2} \mathrm{O}_{2}\right)$ but the $\mathrm{C}_{5} \mathrm{H}_{8} \mathrm{D}_{3} \mathrm{~N}_{2} \mathrm{O}$ ion. In general, $\mathrm{y}$ ions $\left(\mathrm{y}_{5}, \mathrm{y}_{4}\right.$, and $\mathrm{y}_{3}$ series at $m / z 403,346$, and 289, respectively) exchange more slowly than $b_{2}$. Accurate mass measurements were, again, essential to assign the ion at $m / z 287.1160$ as the mono-deuterated $b_{5}$ ion $\left(\mathrm{C}_{10} \mathrm{H}_{15} D_{N_{5}} \mathrm{O}_{5}\right)$. The corre- 


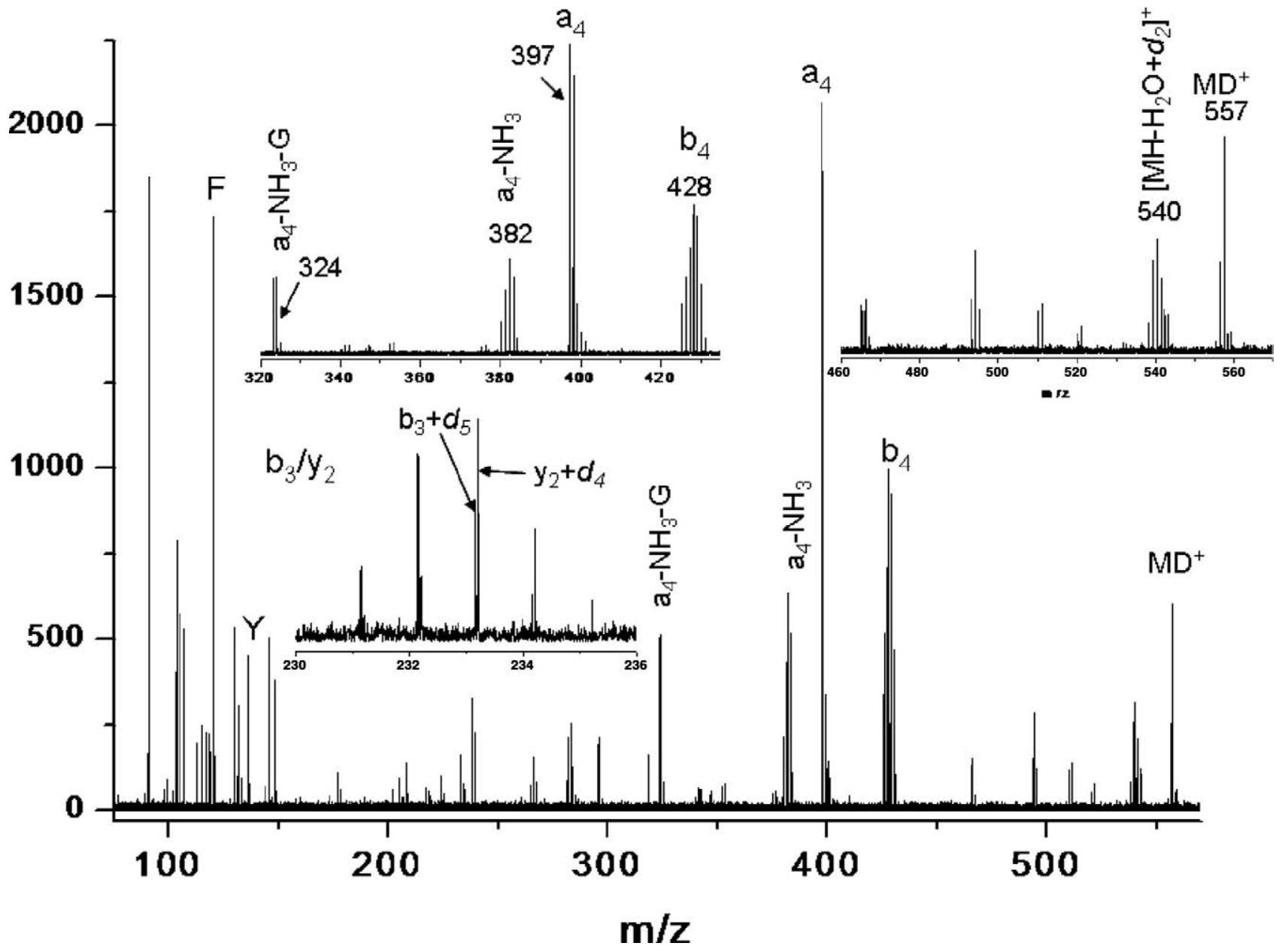

Figure 1. SORI $(0.5 \mathrm{~V}, 1000 \mathrm{~ms}) \mathrm{H} / \mathrm{D}$ exchange spectrum of protonated leucine enkephalin. The SORI (Ar) ion activation was followed by a $10 \mathrm{~s} \mathrm{H} / \mathrm{D}$ exchange with $\mathrm{CD}_{3} \mathrm{OD}$ at $8.5 \times 10^{-7}$ torr.

sponding ion with water loss $\left(\mathrm{m} / \mathrm{z} 268, \mathrm{C}_{10} \mathrm{H}_{14} \mathrm{~N}_{5} \mathrm{O}_{4}\right)$ does not exchange under the same conditions.

No significant HDX processes have been observed for either the doubly charged Gramicidin $\mathrm{S}$ or most of its SORI fragments within 300 s at $4.7 \times 10^{-7}$ torr $\mathrm{CD}_{3} \mathrm{OD}$ (see Figure S2 and Scheme S1 in Supplementary Material). This can be attributed to a more rigid cyclic precursor ion structure. Nevertheless, ring opening occurs, leading to the following main fragments and maximum $\mathrm{H} / \mathrm{D}$ exchanges: $\mathrm{F}\left(d_{0}\right),[\mathrm{PV}-\mathrm{CO}]^{+}\left(d_{1}\right), \mathrm{PV}$ $\left(d_{2}\right), \operatorname{LPV}\left(d_{0}\right),\left[\mathrm{M}+2 \mathrm{H}-\mathrm{FL}^{+}\left(d_{1}\right), \operatorname{LFPV}\left(d_{4}\right)\right.$, and $] \mathrm{M}+$ $\mathrm{H}-\mathrm{FL}^{+}\left(d_{1}\right)$.

As another model study, multiply charged ubiquitin ions have also been investigated. Typical SORI and SORI-RE spectra on the +10 charge state precursor were published in Reference [8]. Here we just note that significant differences were found in the HDX rates for the most prominent fragment ions. The general observation is that the HDX rate is faster for ions with higher charge states. Not surprisingly, though, the fragment ion sequence is also important. For example, the higher charge state $\mathrm{y}_{24}{ }^{4+}$ ion exchanges slower than the triply charged $\mathrm{y}_{18}{ }^{3+}$ (spectrum not shown).
Finally, we note that we are currently using the SORI(RE)-HDX method to investigate sequence scrambling [17] of $b$ ions that occurs by cyclization/ring opening for leucine enkephalin analogs [18]. Based on normalized HDX ion intensity plots as a function of time, we have observed differences in relative HDX kinetic rates for different fragments, which can be attributed to cyclic versus linear fragment ion structures.

\section{Conclusions}

We propose to use gas-phase H/D exchange to qualitatively probe the structure of peptide/protein fragments generated by SORI(RE)-CID. The main advantage of the technique is that the relative $H / D$ exchange rates are simultaneously determined for all fragments and the surviving precursor. The relative differences in $\mathrm{H} / \mathrm{D}$ exchange rates can be correlated to different ion structures (e.g., cyclic versus linear, fixed charge versus mobile proton, etc.). Although the method can conveniently be applied with (low-resolution) quadrupole ion traps, accurate mass measurements are especially valuable for assigning isobaric ions. We believe that the 


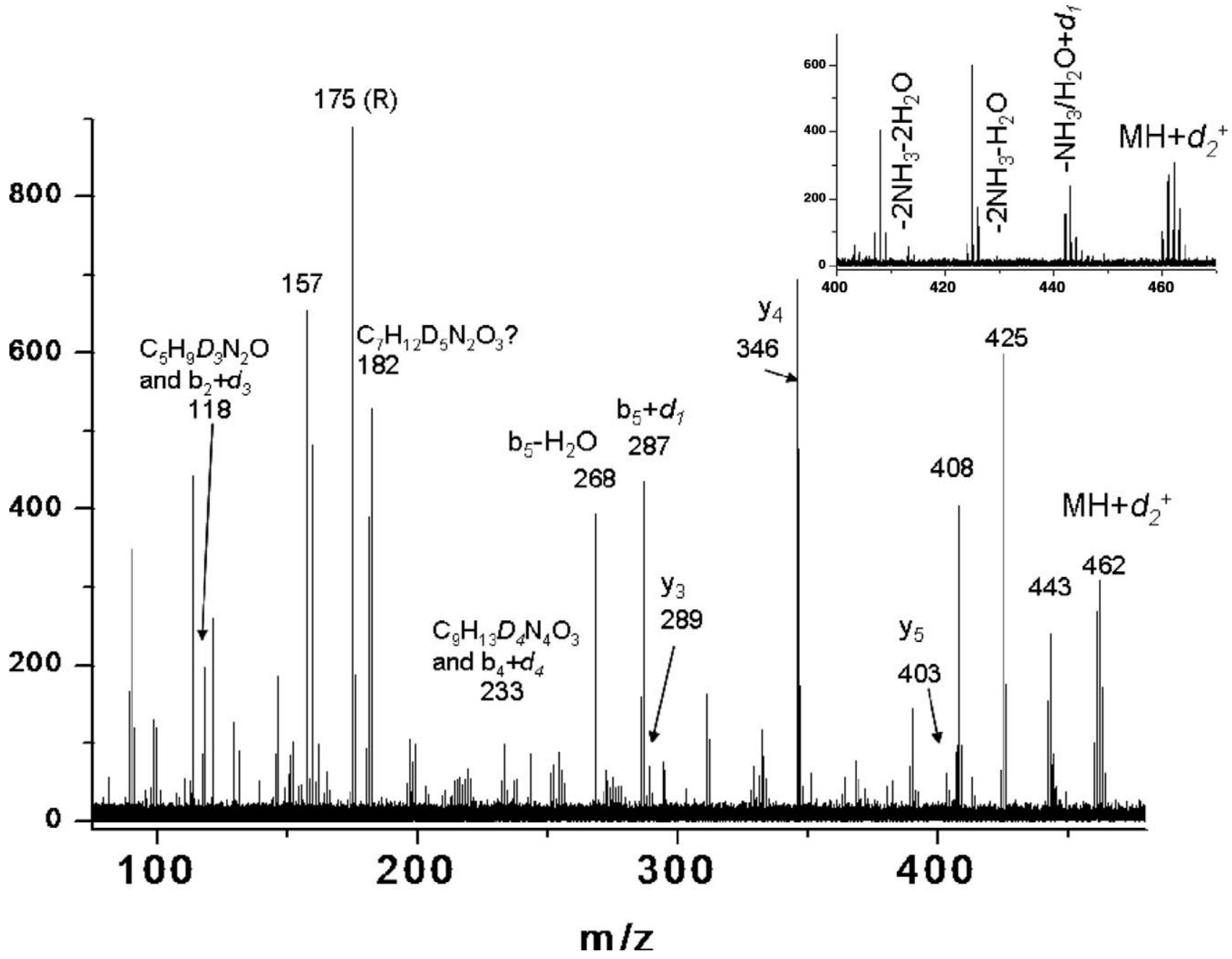

Figure 2. SORI(RE)-HDX spectrum of protonated $\mathrm{G}_{5} \mathrm{R}$. The $\mathrm{MH}^{+}$was activated by a SORI $(2 \mathrm{~V}, 500 \mathrm{~ms})$ pulse followed by a RE (100V, $10 \mu \mathrm{s})$ excitation with a $30 \mathrm{~ms}$ gap in between. The HDX time was $30 \mathrm{~s}$.

SORI(RE)-HDX method is adequate to probe heterogeneous fragment and/or precursor ion populations and can provide useful information on peptide fragmentation pathways.

\section{Acknowledgments}

The author greatly appreciates the fruitful discussions with Dr. Béla Paizs (DKFZ, Heidelberg, Germany) and Professor Vicki Wysocki (Department of Chemistry, University of Arizona).

\section{References}

1. Dongré, A. R.; Jones, J. L.; Somogyi, Á.; Wysocki, V. H. Influence of Peptide Composition, Gas-Phase Basicity, and Chemical Modification on Fragmentation Efficiency: Evidence for the Mobile Proton Model. J. Am. Chem. Soc. 1996, 118, 8365-8374.

2. Wysocki, V. H.; Tsaprailis, G.; Smith, L. L.; Breci, L. A. Mobile and Localized Protons: A Framework for Understanding Peptide Dissociation. J. Mass Spectrom. 2000, 35, 1399-1406.

3. Paizs, B.; Suhai, S. Fragmentation Pathways of Protonated Peptides. Mass Spectrom. Rev. 2005, 24, 508-548.

4. Campbell, S.; Rodgers, M. T.; Marzluff, E. M.; Beauchamp, J. L. Structural and Energetic Constraints on Gas Phase Hydrogen/Deuterium Exchange Reactions of Protonated Peptides with $\mathrm{D}_{2} \mathrm{O}, \mathrm{CD}_{3} \mathrm{OD}, \mathrm{CD}_{3} \mathrm{CO}_{2} \mathrm{D}$, and ND3. J. Am. Chem. Soc. 1994, 116, 9765-9766.

5. Herrmann, K. A.; Wysocki, V. H.; Vorpagel, E. R. Computational Investigation and $\mathrm{H} / \mathrm{D}$ Exchange of the Fixed Charged Derivative Tris (2,4,6-trimethoxyphenyl) phosphonium: Implications for the Aspartic Acid Cleavage Mechanism. J. Am. Soc. Mass Spectrom. 2005, 16, 1067-1080.

6. Somogyi, Á.; Pasilis, S. P.; Pemberton, J. E. Electrospray Ionization of Uranyl-Citrate Complexes: Adduct Formation and Ion-Molecule Reactions in 3D Ion Trap and Ion Cyclotron Resonance Trapping Instruments. Int. J. Mass Spectrom. 2007, 265, 281-294.

7. Reid, G. E.; Simpson, R. J.; O'Hair, R. A. J. Probing the Fragmentation Reactions of Protonated Glycine Oligomers via Multistage Mass Spectrometry and Gas Phase Ion-Molecule Hydrogen/Deuterium Exchange. Int. J. Mass Spectrom. 1999, 190-191, 209-230.

8. Herrmann, K. A.; Somogyi, Á.; Wysocki, V. H.; Drahos, L.; Vékey, K. Combination of Sustained Off-Resonance Irradiation and On-Resonance Excitation in FT-ICR for the Enhancement of Higher Energy Fragmentation Pathways. Anal. Chem. 2005, 77, 7626-7638.

9. Polfer, N. C.; Oomens, J.; Suhai, S.; Paizs, B. Spectroscopic and Theoretical Evidence for Oxazolone Ring Formation in Collision Induced Dissociation of Peptides. J. Am. Chem. Soc. 2005, 127, $17154-17155$

10. Polfer, N. C.; Oomens, J.; Suhai, S.; Paizs, B. Infrared Spectroscopy and Theoretical Studies on Gas-Phase Protonated Leu-enkephalin and Its Fragments: Direct Experimental Evidence for the Mobile Proton. J. Am. Chem. Soc. 2007, 129, 5887-5897.

11. Polfer, N. C.; Bohrer, B. C.; Plasencia, M. D.; Paizs, B.; Clemmer, D. E. On the Dynamics of Fragment Isomerization in Collision-Induced Dissociation of Peptides. J. Phys. Chem. A. 2008, 112, 1286-1293.

12. Riba-Garcia, I.; Giles, K.; Bateman, R. H.; Gaskell, S. J. Evidence for Structural Variants of a- and b-Type Peptide Fragment Ions Using Combined Ion Mobility/Mass Spectrometry. J. Am. Soc. Mass Spectrom. 2008, 19, 609-613.

13. Jiao, C. Q.; Ranatunga, D. R. A.; Vaughn, W. E.; Freiser, B. S. J. A Pulsed Leak Valve for Use with Ion Trapping Mass Spectrometers. Am. Soc. Mass Spectrom. 1996, 7, 118-122. 
14. Ballard, K. D.; Gaskell, S. J. Dehydration of Peptide $[\mathrm{M}+\mathrm{H}]^{+}$Ions in the Gas Phase. J. Am. Soc. Mass Spectrom. 1993, 4, 477-481.

15. Vachet, R. W.; Bishop, B. M.; Erickson, B. W.; Glish, G. L. Novel Peptide Dissociation: Gas-Phase Intramolecular Rearrangement of Internal Amino Acid Residues. J. Am. Chem. Soc. 1997, 119, 5481-5488.

16. Cooper, T.; Talaty, E.; Grove, J.; Van Stipdonk, M.; Suhai, S.; Paizs, B. Isotope Labeling and Theoretical Study of the Formation of $\mathrm{a}_{3}{ }^{*}$ Ions from Protonated Tetraglycine J. Am. Soc. Mass Spectrom. 2006, 17, $1654-1664$.

17. Harrison, A. G.; Young, A. B.; Bleiholder, C.; Suhai, S.; Paizs, B. Scrambling of Sequence Information in Collision-Induced Dissociation of Peptides. J. Am. Chem. Soc. 2006, 128, 10364-10365.

18. Galhena, A.; Perkins, B.; Somogyi, A.; Wysocki, V. H. Gas-phase Intramolecular Rearrangement of Peptides and Their Fragments, unpublished. 